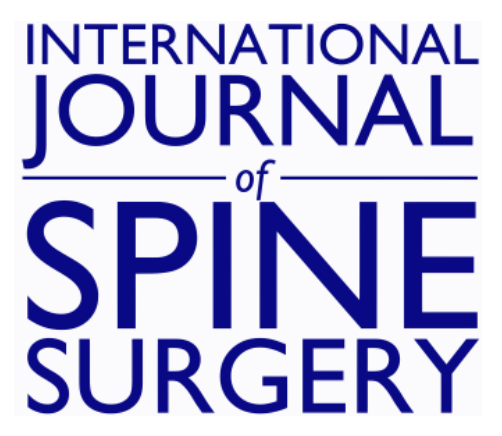

\title{
Economics of Cervical Disc Replacement
}

Kris Radcliff and Richard D Guyer

Int J Spine Surg 2020, 14 (s2) S67-S72

doi: https://doi.org/10.14444/7093

http://ijssurgery.com/content/14/s2/S67

This information is current as of April 26, 2023.

Email Alerts Receive free email-alerts when new articles cite this article. Sign up at: http://ijssurgery.com/alerts 


\title{
Economics of Cervical Disc Replacement
}

\author{
KRIS RADCLIFF, MD, ${ }^{1}$ RICHARD D GUYER, $\mathrm{MD}^{2}$ \\ ${ }^{1}$ Department of Orthopedic Surgery, Thomas Jefferson University, Rothman Institute, Egg Harbor Township, New Jersey, ${ }^{2}$ Texas Back Institute Research \\ Foundation, Texas Back Institute, Plano, Texas
}

\begin{abstract}
Background: Although extensive reports of clinical outcome after cervical disc replacement (CDR) and anterior cervical discectomy and fusion exist, few reviews of the cost-effectiveness research in cervical spine surgery exist. The purpose of this study was to review the concepts of cost-effectiveness research, the various approaches to costeffectiveness studies in the context of cervical spine surgery, and some of the literature results.

Methods: Review article describing cost-effectiveness research concepts, methodology, and results. The article reviews the concept of value, cost, utility, incremental cost-effectiveness ratio, and recent research.

Results: Mixed data on cost-effectiveness of CDR compared with fusion exist. Notably, several studies performed within the last 5 years that use prospectively collected utility scores, costs, and adverse event calculations demonstrate a significant cost savings associated with CDR compared with fusion.

Conclusions: The recent literature confirms that, in properly selected patients, CDR is more effective and less costly over a 7-year time horizon for patients with symptomatic degenerative disc disease. The primary driver of the differential in cost effectiveness is the difference in secondary surgery rates.

Level of Evidence: Level 5

Clinical Relevance: In properly selected patients, CDR is more effective and less costly over a 7-year time horizon for patients with symptomatic degenerative disc disease.

Special Issue-Cervical Spine

Keywords: cervical total disc replacement, anterior cervical discectomy and fusion, single-level degenerative disc disease, cost effectiveness
\end{abstract}

\section{INTRODUCTION}

Seven cervical disc replacements (CDRs) have been Food and Drug Administration (FDA) approved after completion of FDA investigational device exemption (IDE) studies in 2007. ${ }^{1}$ Cervical total disc replacement is an increasingly popular technique for the treatment of cervical radiculopathy. ${ }^{2-4}$ Several level 1 and 2 trials have demonstrated outcomes of CDR to be equivalent or superior to anterior cervical discectomy and fusion (ACDF) ${ }^{5-8}$ Anterior cervical decompression and fusion has been the gold standard treatment for cervical radiculopathy and myelopathy at 1 and 2 levels due to the direct decompression, safety, and excellent outcomes at long-term follow up. However, ACDF may potentiate degenerative changes at adjacent, unfused levels of the spine. ${ }^{9}$ Symptomatic adjacent segment disease affects $25 \%$ of all patients who undergo an ACDF by 10 years with more than two-thirds of patients failing nonoperative therapy and requiring addition operative interventions. ${ }^{9}$ After arthrodesis, increased mechanical stresses are observed at adjacent levels, ${ }^{10,11}$ potentially leading to adjacent segment pathology. ${ }^{12-16}$ By preserving motion at the index level, CDR has been shown to reduce the incidence of symptomatic degeneration at adjacent levels. ${ }^{17-19}$

Value is defined in health care research as the relationship between cost and quality. ${ }^{20}$ Cost is typically expressed as a cost-effectiveness ratio of the cost of an intervention related to its quality. However, there have been fewer analyses of costeffectiveness of disc replacement and ACDF. The purpose of this study was to review the methodology and findings of the recent literature on cost effectiveness of CDR versus ACDF for the treatment of patients with symptomatic degenerative disc disease.

\section{Concepts in Cost-Effectiveness Research: Cost}

Cost is broadly categorized into direct costs and indirect costs. Direct costs are direct expenses incurred during the delivery of health care, such as implant costs, surgical fees, and prescription costs. 
Indirect costs are monetary losses related to the delivery of health care that are not direct expenditures. Lost wages, unpaid caregiver time (such as family leave), and lost productivity are examples of indirect health care costs. Indirect costs are more difficult to quantify. ${ }^{21,22}$ Practically, since the length of hospital stay, therapy protocol, medication usage, imaging, perioperative complications, and readmission rates are comparable between ACDF and $\mathrm{CDR}$, the difference in reoperation rates is a significant driver of direct costs and thus overall costs. $^{23}$

A significant limitation of cost-effectiveness research in CDR is the lack of a standardized method for calculating costs. Although it is obvious that a thorough, standardized cost accounting is critical to successful cost-effectiveness research, significant variability in the method of cost assessment in the spine literature affects the outcome of some studies. ${ }^{24}$ The most rigorous approach to cost accounting involves the use of complex, thorough patient activity journals to track health care consumption and indirect costs. ${ }^{21,22}$ However, such journals are seldom used. Even assessment of direct costs are confounded by confidential contracts of surgeon and hospital reimbursements, pharmaceutical costs, anesthesia cost, imaging center costs, and surgeon and regional variability in costs. ${ }^{23}$ For this reason, cost-effectiveness research is often reported using physician and hospital charges, rather than reimbursement. However, using charges as the basis for cost-effectiveness research is suspect since there may not be a direct correlation between charges and reimbursement. ${ }^{25}$ For example, hospital charges in spine surgery have been increasing in the past decade despite a decrease in length of stay over the same time period. ${ }^{26}$ In addition, charges and reimbursement may not be related to the actual labor costs and resource consumption necessary for health care delivery. New analyses using advanced time-based activity costing techniques have indicated substantially increased time investments and therefore costs for common spine surgeries relative to the reimbursement. ${ }^{27}$

\section{Concepts in Cost-Effectiveness Research: Utility}

Clinical outcome has been widely studied after spine surgery and, in some cases, compared with other disease conditions using common outcome measures such as the 36-item Short Form Survey $\left(\right.$ SF-36.) ${ }^{28}$ However, in cost-effectiveness research, the outcome portion of the value equation is assessed using health utility scores. Utility scores are a standard benchmark scale of the quality of life at various health care states between perfect health (which by definition has a utility score of 1) and death (which by definition has a utility score of 0 ). Utility scores are measured in quality adjusted life years (QALYs). Utility scores are calculated using specific instruments (mainly the EuroQol-5 dimenson (EQ5D) or the Health Utility Index). The health utility of various disease states have been described in previous literature from direct patient surveys (such as, "How much time would you trade to not have this condition?"). ${ }^{29-31}$ Utility scores can also be calculated from general outcome measures (such as Short Form-6 dimension (SF6D) or some diseasespecific measures (such as Neck Disability Index). ${ }^{32}$ In contrast to general outcome measures, utility scores employ preference weighting, since they are derived from surveys that ask the individual to weigh their disease state versus their overall health and life. Reoperations may also affect clinical outcomes since they generally occur for ongoing or unresolved symptomatology. ${ }^{33}$

When comparing CDR with ACDF, specific limitations in the outcome research may affect cost-effectiveness calculations. The reported utility scores in the large clinical trials may be affected by affirmation bias since the patients were not blinded to the intervention. ${ }^{34}$ Thus, some critics suspect that patient euphoria about participating in a clinical trial may overcome a poor clinical outcome. However, it is not clear that such affirmation bias would persist long term or would affect utility scores. Additionally, in at least 1 study, the ACDF secondary surgery rate was higher than that which was expected in the literature and in a concordant group of patients treated at the same institution. ${ }^{35}$ This finding may indicate that increased surveillance and scrutiny of ACDF outcomes in IDE study conditions. Utility values may also underestimate the impact of some spine-specific factors on patient quality of life. ${ }^{36}$ Finally, it is not clear if the IDE study results can be generalized to the population since the IDE studies included only a select group of patients. ${ }^{37}$

\section{Concepts in Cost-Effectiveness Research: Incremental Cost-Effectiveness Ratio}

Thus, cost effectiveness of an intervention is defined as the relationship between cost over a 
specific period of QALY (cost/QALY). To compare the cost effectiveness of 2 interventions, an incremental cost-effectiveness ratio (ICER) is most often calculated. ${ }^{5}$ The ICER is the ratio of change in costs to the change in QALY. For example, comparing surgery A and surgery B, the ICER is (Cost SurgeryA $_{-}$ Cost $\left._{\text {SurgeryB }}\right) /\left(\right.$ QALY $_{\text {SurgeryA }}-$ QALY $\left._{\text {SurgeryB }}\right)$.

\section{Critical Literature Review}

Early cost-effectiveness analyses comparing ACDF and CDR used data gathered from different sources. For example, in 2013, Qureshi et $\mathrm{al}^{38}$ performed a cost-effectiveness analysis of CDR versus fusion using outcomes data from the medical literature, complications data from the Nationwide Inpatient Sample, and gross physician costs from the mean Medicare reimbursement. A second study evaluated cost effectiveness using complications and outcome data from the literature, utility scores from an IDE study dataset, and physician costs from the Medicare reimbursement. ${ }^{39}$ Both studies suggested that CDR was cost savings relative to ACDF in the long term. In both studies, the cost effectiveness of CDR was heavily dependent on the reoperation rate in the model, and long-term data were suggested. However, both studies were limited by the shortterm follow up, the heterogenous data sources, and the lack of specific patient-level data about adverse events.

Recent cost-effectiveness analyses within the last 5 years have substantially improved scientific rigor by using the same dataset for estimation of costs and outcomes. Warren et $\mathrm{al}^{40}$ used single-center data from 31 patients enrolled in the ProDisc C IDE study. Physician and hospital costs were derived from local hospital data. Additionally, the outcome data were derived from direct chart review at the host institution. The authors found ACDF to be more costly but more effective than CDR at 2 years. ${ }^{40}$ However, this study did not include postoperative health care resource utilization, including secondary surgery.

Overley et $\mathrm{al}^{41}$ recently presented a very sophisticated analysis of cost effectiveness of 2-level ACDF versus CDR using data from the Prestige IDE trial. The authors used utility data from the Prestige LP IDE trial. Cost data were derived from Current Procedural Terminology (CPT) and ICD costs of the initial hospital stay. Probabilities of complications were derived from the IDE study dataset. The authors considered complications within 90 days after the index surgery. A generic cost was assigned to all perioperative complications (which was determined to have a probability of 0.11 ACDF and 0.081 CDR). After 90 days, only secondary surgeries were considered again using probabilities from the same dataset. The authors found that 2-level CDR and ACDF are both costeffective strategies at 5 years. Neither strategy was found to be more cost effective with an ICER greater than the $\$ 50000 / \mathrm{QALY}$ willingness to pay (WTP) threshold.

Unfortunately, tremendous variability still exists in the methodology of calculating direct costs in CDR studies. For example, using the ZimmerBiomet Mobi $\mathrm{C}$ database, Ament et $\mathrm{al}^{42}$ reported that the 5-year cost of a 2-level CDA cost was $\$ 23459$. In contrast, Overley et $\mathrm{al}^{41}$ reported that the cost of a 2-level CDA with a 5-year follow up was $\$ 130417$. The reason for the difference in cost calculation is due to differences in the method of calculation of costs. Overley et $\mathrm{al}^{41}$ used International Classification of Diseases, Ninth Revision, diagnosis-related group and CPT codes specific for each surgical procedure. Ament et $\mathrm{al}^{42}$ used the IDE study database. The authors included specific costs of postoperative visits, postoperative medications, and adverse events that required secondary procedures. Adverse events that did not require secondary surgery (such as dysphagia) were excluded. The authors found that the ICER for CTDR was -\$165 103 per QALY. Furthermore, the authors determined that the ICER for CTDR remained below the US willingness-to-pay threshold of $\$ 50000$ per QALY in all scenarios. ${ }^{42}$

Another methodology to overcome the limitation of charges is use of payer data on actual expenditures. Radcliff et $\mathrm{al}^{43}$ conducted a cost-minimization analysis using a single dataset from a health care payer (Blue Health Intelligence). The authors found reduced rates of expenditure by the payer on the index surgery costs and the posthospital health care resource use in CDR versus ACDF patients (\$29 697 versus $\$ 42486, P<.05$ through 7 years). Even excluding index-level surgery costs, the expenditure per member per month was lower in CDR patients through 36 months. Additionally, the reoperation rate was lower in CDR patients. ${ }^{43}$ In addition to the avoidance of charge data, this study of real-world data (outside of IDE study conditions) may have been less susceptible to industry funding bias compared with the IDE studies. 
Radcliff et $\mathrm{al}^{43}$ performed a retrospective cost analysis of a prospective database from an IDE study and postapproval study. The authors calculated utility scores calculated from SF-36 survey of patients in the Prodisc-C IDE and Post-Approval Study. In addition, the authors directly evaluated each chart for specific adverse events that were outside of the normal course of care (such as a swallow study or otolaryngologist consult for dysphagia at 3 months postoperatively). Interventional pain procedures and postoperative physical therapy outside of the normal course of treatment were also documented. In this manner, the authors attempted to capture all clinical events that could incur a direct cost. Costs were imputed to each clinical event. The authors found that the cumulative costs of ACDF and CDR at 7 years were \$42 486 and \$29697, respectively. Utility score measurements demonstrated an improvement in QALY in CDR over ACDF (4.36 ACDF versus $4.52 \mathrm{CDR}$ ) at 7 years. Thus, CDR was a dominant strategy, as it was found to be less expensive but also more effective. The ICER was $-\$ 79$ 931.25.

\section{Future Directions}

Future studies may report comparative effectiveness using measures other than ICER. As indicated above, both the Ament et $\mathrm{al}^{42}$ study and the Radcliff et $\mathrm{al}^{43}$ study reported negative ICERs. A negative sign on the ICER in these studies indicates that the CDR technology is less expensive and more effective. However, the negative sign could also indicate that the technology was more expensive and less effective. Thus, without additional clinical information, the interpretation of the negative sign of the ICER could have completely different implications. Thus, in health economics studies, a net monetary benefit is also reported as an alternative representation of ICERs, representing a singular monetary measure of incremental cost effectiveness at a specific willingness-to-pay threshold. ${ }^{44,45}$ Net monetary benefit (NMB) overcomes several limitations inherent in the use of ICERs to describe the results of cost-effectiveness analyses. Net monetary benefit is derived by rearranging the ICER calculation into a linear function by converting QALYs into monetary units at a specific willingness-to-pay threshold, as follows: $\mathrm{NMB}=$ (willingness to pay $\times \Delta$ QALYs) $-\Delta$ costs. ${ }^{44}$

By definition, health interventions with positive incremental $\mathrm{NMB}$ values (ie, greater than $\$ 0$ ) are cost effective at specified thresholds for the value assigned to an incremental QALY. ${ }^{44}$

Radcliff et $\mathrm{al}^{43}$ determined that the mean NMB of \$20 679 (\$6 053-\$35 377) at a willingness-to-pay threshold of $\$ 50000 / \mathrm{QALY}$. CTDR was cost effective relative to ACDF at WTP thresholds ranging from $\$ 10000 / \mathrm{QALY}$ to $\$ 100000 / \mathrm{QALY}$.

Additionally, as discussed above, no data indicated that the current charges of health care are actually representative of the expenses incurred in the delivery of health care. For example, when purchasing an automobile, it is not uncommon to review a factory invoice to obtain a basic understanding of the worth of the automobile. The factory invoice is thought to represent the cost to the manufacturer for goods and labor to assemble the car and is a common starting point for negotiation for buyer and seller. Then price negotiations with the dealer center on a specific markup (usually $3 \%-5 \%$ ) that represents profit for the dealer. However, in health care, prices are based at legacy levels without a clear basis on the value of the goods and services. A methodology called timedriven activity-based costing (TDABC) analysis attempts to quantify the specific cost of the delivery of health care goods and services. Time-driven activity-based costing assesses and assigns a cost to incremental time spent by various health care parties (eg, patient spent 5 minutes in registration $X$ the salary of a registration clerk per minute, 15 minutes with a physical therapist $\times$ the physical therapist salary per minute, 2 hours with a post anesthesia care unit ( PACU ) nurse $\times$ PACU nurse hourly salary, etc.) to determine actual health care costs. ${ }^{46}$ Schroeder et $\mathrm{al}^{46}$ reported that using this methodology, the total direct cost through 90 days for a single or 2-level ACDF is \$29 299. To date, no specific study of ACDF versus CDR has used TDABC analysis. However, given the increased technical difficulty of disc replacement relative to $\mathrm{ACDF}$, it is possible that the index surgery will be slightly more costly due to the use of fluoroscopy and careful, limited resection.

\section{CONCLUSIONS}

Cost-effectiveness research fundamentally elucidates the challenge to payers, patients, and providers of health care is to maximize net benefits obtained from health care expenditures. A consistent criticism is that new health care technologies are more expensive than existing alternatives, while 
their efficacy is unproven. Ideally, the best interventions will not only optimize outcomes but will also in turn help curb health care spending in the long term. In the context of $C D R$ versus $A C D F$, cost-effectiveness studies have become increasingly sophisticated in the past decade. Future methods such as TDABC and reporting of NMB may better illuminate the true cost of $\mathrm{ACDF}$ and CDR. Most of the recent literature indicates that CDR not only results in a superior clinical outcome but also is cost saving relative to ACDF in properly selected patients. The largest driver of cost savings is the reduced rate of secondary surgery in CDR patients. With longer-term follow up, the financial benefit of CDR will likely be magnified.

\section{REFERENCES}

1. Baaj AA, Uribe JS, Vale FL, Preul MC, Crawford NR. History of cervical disc arthroplasty. Neurosurg Focus. 2009;27(3):E10. doi:10.3171/2009.6.FOCUS09128

2. Qureshi SA, Koehler SM, Lu Y, Cho S, Hecht AC. Utilization trends of cervical artificial disc replacement during the FDA investigational device exemption clinical trials compared to anterior cervical fusion. J Clin Neurosci. 2013;20(12):1723-1726.

3. Lu Y, McAnany SJ, Hecht AC, Cho SK, Qureshi SA. Utilization trends of cervical artificial disc replacement after FDA approval compared with anterior cervical fusion: adoption of new technology. Spine (Phila Pa 1976). 2014;39(3):249255.

4. Baird EO, Egorova NN, McAnany SJ, Qureshi SA, Hecht AC, Cho SK. National trends in outpatient surgical treatment of degenerative cervical spine disease. Global Spine $J$. 2014;4(3):143-510.

5. Tarazona DA, Schroeder GD, Vaccaro AR, Radcliff KE. Value of cervical disk arthroplasty. Clin Spine Surg. 2018; doiI:10.1097/BSD.0000000000000768

6. Lanman TH, Burkus JK, Dryer RG, Gornet MF, McConnell J, Hodges SD. Long-term clinical and radiographic outcomes of the Prestige LP artificial cervical disc replacement at 2 levels: results from a prospective randomized controlled clinical trial. J Neurosurg Spine. 2017;27(1):7-19.

7. Vaccaro A, Beutler W, Peppelman W, et al. Long-term clinical experience with selectively constrained SECURE-C cervical artificial disc for 1-level cervical disc disease: results from seven-year follow-up of a prospective, randomized, controlled investigational device exemption clinical trial. Int $J$ Spine Surg. 2018;12(3):377-387.

8. Gornet MF, Burkus JK, Shaffrey ME, Argires PJ, Nian H, Harrell FE Jr. Cervical disc arthroplasty with PRESTIGE LP disc versus anterior cervical discectomy and fusion: a prospective, multicenter investigational device exemption study. J Neurosurg Spine. 2015;23(5):558-573.

9. Hilibrand AS, Carlson GD, Palumbo MA, Jones PK, Bohlman HH. Radiculopathy and myelopathy at segments adjacent to the site of a previous anterior cervical arthrodesis. $J$ Bone Joint Surg Am. 1999;81(4):519-528.
10. Auerbach JD, Anakwenze OA, Milby AH, Lonner BS, Balderston RA. Segmental contribution toward total cervical range of motion: a comparison of cervical disc arthroplasty and fusion. Spine (Phila Pa 1976). 2011;36(25):E1593-E1599.

11. Anakwenze OA, Auerbach JD, Milby AH, Lonner BS, Balderston RA. Sagittal cervical alignment after cervical disc arthroplasty and anterior cervical discectomy and fusion: results of a prospective, randomized, controlled trial. Spine (Phila Pa 1976). 2009;34(19):2001-2007.

12. Harrod CC, Hilibrand AS, Fischer DJ, Skelly AC. Adjacent segment pathology following cervical motion-sparing procedures or devices compared with fusion surgery: a systematic review. Spine (Phila Pa 1976). 2012;37(22 Suppl):S96-S112.

13. Lawrence BD, Hilibrand AS, Brodt ED, Dettori JR, Brodke DS. Predicting the risk of adjacent segment pathology in the cervical spine: a systematic review. Spine (Phila Pa 1976). 2012;37(22 Suppl):S52-S64.

14. Botelho RV, Moraes OJ, Fernandes GA, Buscariolli Ydos S, Bernardo WM. A systematic review of randomized trials on the effect of cervical disc arthroplasty on reducing adjacent-level degeneration. Neurosurg Focus. 2010;28(6):E5. doi:10.3171/2010.3.focus 1032 .

15. Jawahar A, Cavanaugh DA, Kerr EJ 3rd, Birdsong EM, Nunley PD. Total disc arthroplasty does not affect the incidence of adjacent segment degeneration in cervical spine: results of 93 patients in three prospective randomized clinical trials. Spine J. 2010;10(12):1043-1048.

16. Fallah A, Akl EA, Ebrahim S, et al. Anterior cervical discectomy with arthroplasty versus arthrodesis for single-level cervical spondylosis: a systematic review and meta-analysis. PLoS One. 2012;7(8):e43407. doi:10.1371/journal.pone.0043407

17. Zigler JE, Delamarter R, Murrey D, Spivak J, Janssen M. ProDisc-C and ACDF as surgical treatment for single level cervical symptomatic degenerative disc disease: five-year results of an FDA study. Spine (Phila Pa 1976). 2012. doi:10.1097/ BRS.0b013e318278eb38

18. Delamarter RB, Zigler J. Five-year reoperation rates, cervical total disc replacement versus fusion, results of a prospective randomized clinical trial. Spine (Phila Pa 1976). 2012; doi:10.1097/BRS.0b013e3182797592

19. Robertson JT, Papadopoulos SM, Traynelis VC. Assessment of adjacent-segment disease in patients treated with cervical fusion or arthroplasty: a prospective 2-year study. $J$ Neurosurg Spine. 2005;3(6):417-423.

20. Porter ME. What is value in health care? $N$ Engl J Med. 2010;363(26):2477-2481.

21. Tosteson AN, Lurie JD, Tosteson TD, et al. Surgical treatment of spinal stenosis with and without degenerative spondylolisthesis: cost-effectiveness after 2 years. Ann Intern Med. 2008;149(12):845-853.

22. Tosteson AN, Skinner JS, Tosteson TD, et al. The cost effectiveness of surgical versus nonoperative treatment for lumbar disc herniation over two years: evidence from the Spine Patient Outcomes Research Trial (SPORT). Spine (Phila Pa 1976). 2008;33(19):2108-2115.

23. Chotai S, Sivaganesan A, Parker SL, Sielatycki JA, McGirt MJ, Devin CJ. Drivers of variability in 90-day cost for elective anterior cervical discectomy and fusion for cervical degenerative disease. Neurosurgery. 2018;83(5):898-904.

24. Alvin MD, Miller JA, Lubelski D, et al. Variations in cost calculations in spine surgery cost-effectiveness research. 
Neurosurg Focus. 2014;36(6):E1. doi:10.3171/2014.3.FOCUS1447

25. Skolasky RL, Riley LH 3rd. Medicare charges and payments for cervical spine surgery: association with hospital characteristics. Spine (Phila Pa 1976). 2015;40(16):E936-E942.

26. Jain N, Phillips FM, Shimer AL, Khan SN. Surgeon reimbursement relative to hospital payments for spinal fusion: trends from 10-year Medicare analysis. Spine (Phila Pa 1976). 2018;43(10):720-731.

27. Pierce JT, Kanuparthi P, McShane BJ, Welch RL, Marcotte PJ, Welch WC. A prospective detailed time analysis study of 18 patients undergoing elective single-level open lumbar microdiscectomy spinal surgery compared with Centers for Medicare and Medicaid Services reimbursement guidelines. World Neurosurg. 2018;119:e666-e670.

28. Polly DW Jr, Glassman SD, Schwender JD, et al. SF-36 PCS benefit-cost ratio of lumbar fusion comparison to other surgical interventions: a thought experiment. Spine (Phila $\mathrm{Pa}$ 1976). 2007;32(11 Suppl):S20-S26.

29. Qureshi S, Goz V, McAnany S, et al. Health state utility of patients with single-level cervical degenerative disc disease: comparison of anterior cervical discectomy and fusion with cervical disc arthroplasty. J Neurosurg Spine. 2014;20(5):475479 .

30. Carreon LY, Glassman SD, Djurasovic M, et al. Are preoperative health-related quality of life scores predictive of clinical outcomes after lumbar fusion? Spine (Phila Pa 1976). 2009;34(7):725-730.

31. Cher DJ, Reckling WC. Quality of life in preoperative patients with sacroiliac joint dysfunction is at least as depressed as in other lumbar spinal conditions. Med Devices (Auckl). 2015;8:395-403.

32. Carreon LY, Anderson PA, McDonough CM, Djurasovic M, Glassman SD. Predicting SF-6D utility scores from the neck disability index and numeric rating scales for neck and arm pain. Spine (Phila Pa 1976). 2011;36(6):490-494.

33. Lu Y, Qureshi SA. Cost-effective studies in spine surgeries: a narrative review. Spine J. 2014;14(11):2748-2762.

34. Radcliff K, Siburn S, Murphy H, Woods B, Qureshi S. Bias in cervical total disc replacement trials. Curr Rev Musculoskelet Med. 2017;10(2):170-176.

35. Singh K, Phillips FM, Park DK, Pelton MA, An HS, Goldberg EJ. Factors affecting reoperations after anterior cervical discectomy and fusion within and outside of a Federal Drug Administration investigational device exemption cervical disc replacement trial. Spine J. 2012;12(5):372-378.

36. Glassman SD, Bridwell KH, Shaffrey CI, et al. Healthrelated quality of life scores underestimate the impact of major complications in lumbar degenerative scoliosis surgery. Spine Deform. 2018;6(1):67-71.

37. Auerbach JD, Jones KJ, Fras CI, Balderston JR, Rushton SA, Chin KR. The prevalence of indications and contraindications to cervical total disc replacement. Spine J. 2008;8(5):711-716.

38. Qureshi SA, McAnany S, Goz V, Koehler SM, Hecht AC. Cost-effectiveness analysis: comparing single-level cervical disc replacement and single-level anterior cervical discectomy and fusion: clinical article. J Neurosurg Spine. 2013;19(5):546554 .
39. McAnany SJ, Overley S, Baird EO, et al. The 5-year costeffectiveness of anterior cervical discectomy and fusion and cervical disc replacement: a Markov analysis. Spine (Phila Pa 1976). 2014;39(23):1924-1933.

40. Warren D, Andres T, Hoelscher C, Ricart-Hoffiz P, Bendo J, Goldstein J. Cost-utility analysis modeling at 2-year follow-up for cervical disc arthroplasty versus anterior cervical discectomy and fusion: a single-center contribution to the randomized controlled trial. Int J Spine Surg. 2013;7:e58-e66.

41. Overley SC, McAnany SJ, Brochin RL, Kim JS, Merrill RK, Qureshi SA. The 5-year cost-effectiveness of two-level anterior cervical discectomy and fusion or cervical disc replacement: a Markov analysis. Spine J. 2018;18(1):63-71.

42. Ament JD, Yang Z, Nunley P, Stone MB, Lee D, Kim KD. Cost utility analysis of the cervical artificial disc vs fusion for the treatment of 2-level symptomatic degenerative disc disease: 5-year follow-up. Neurosurgery. 2016;79(1):135-145.

43. Radcliff K, Lerner J, Yang C, Bernard T, Zigler JE. Seven-year cost-effectiveness of ProDisc-C total disc replacement: results from investigational device exemption and postapproval studies. J Neurosurg Spine. 2016;24(5):760-768.

44. O'Brien BJ, Briggs AH. Analysis of uncertainty in health care cost-effectiveness studies: an introduction to statistical issues and methods. Stat Methods Med Res. 2002;11(6):455468.

45. Petrou S, Gray A. Economic evaluation alongside randomised controlled trials: design, conduct, analysis, and reporting. BMJ (Clin Res Ed). 2011;342:d1548. doi:10.1136/ bmj.d1548

46. Schroeder G, Kepler K, Nicholson K, et al. The Real Cost of ACDF: Time-Driven Activity Based Costing Analysis. Toronto: Cervical Spine Research Society; 2017.

Disclosure and COI: All devices discussed herein are Food and Drug Administration approved for their respective purposes. No compensation was received for time devoted to clinical research or the writing and editing of this manuscript. No portion of the contents of this paper has been presented in abstract or poster form.

Corresponding Author: Kris Radcliff, MD, Department of Orthopedic Surgery, Thomas Jefferson University, 2500 English Creek Avenue, Rothman Institute, Egg Harbor Township, NJ 08234. Phone: (609) 573-3301; Fax: (609) 407-6405; Email: kris.radcliff@rothmaninstitute.com.

Published 30 September 2020

This manuscript is generously published free of charge by ISASS, the International Society for the Advancement of Spine Surgery. Copyright (c) 2020 ISASS. To see more or order reprints or permissions, see http://ijssurgery.com. 